\title{
An Inquiry Into The Demand For Aircraft Noise Abatement \#
}

\author{
Gerald S. McDougall*
}

\section{INTRODUCTION}

Though it is generally recognized that the spatial distribution of environmental characteristics over an urban area influences residential site choice and, therefore, residential property values, little property value analysis has been done on other air pollution-specific environmental problems. $(9,11)$ It is becoming increasingly evident, however, that other nonmarketed joint products of economic activity are as noxious to households as is air pollution. An example of such a joint product is the noise generated by aircraft operations and overflights near residential areas.

The significance of this noise pollution problem is evidenced by the recognition that serious health problems are associated with prolonged exposure to certain critical noise levels (1: 227-236), by the legislated aircraft noise standards now coming into effect, and by the increasing number of court awards to homeowners for trespassing damages due to aircraft overflights. $(10,13)$ Despite this, however, there are few discussions in the literature on the economic effects of aircraft noise pollution, or on household responses to spatial differences in experienced noise intensities. There is little evidence concerning the nature or magnitude of the costs incurred by households because of aircraft operations over residential areas.

The purpose of this investigation, therefore, is to provide insights into household responses to aircraft noise pollution by estimating the implicit demand, as revealed by residential site choice and therefore property values, for aircraft noise abatement (i.e., noise related environmental quality). Given this demand relation it is possible to estimate the compensating variation associated with noise pollution differentials; that is the amount households are willing to pay for an increase in environmental quality associated with a reduction in aircraft noise.

The technique used to estimate the demand relation for noise abatement is the two-step procedure suggested by Freeman (3) and Rosen (12) in their discussions on the interpretation of hedonic regressions. In the first step, the environmental quality-house value gradient is esti-

\#An earlier draft of this paper was presented at the annual meeting of Southern Regional Science Association (April 8-9, 1976) Richmond, Virginia. I would like to thank J. Triplett and L. Sahling for helpful comments.

*Wichita State University. 
mated. For convenience it is assumed that environmental quality (E) is inversely related to noise pollution and that environmental quality can be measured by the reciprocal of noise intensity $(\mathrm{N})$.

$$
\mathrm{E}=\mathrm{E}(\mathrm{N})=1 / \mathrm{N}
$$

From this step are derived estimates of the implicit purchase price for reductions in noise pollution; that is, the value placed on marginal increases in environmental quality associated with decreases in experienced aircraft noise intensities. In the second step, the demand relation for noise abatement is estimated using the implicit prices generated from the first step. The compensating variation associated with a nonmarginal environment improvement is derived by integrating over the estimated demand function. ${ }^{1}$

This approach is based on the presumption that utility maximizing households equate their marginal willingness to pay for environmental quality to the marginal purchase price. Figure 1 shows the environmental quality-house value gradient, $\mathrm{V}(\mathrm{E})$. This curve represents the opportunity locus for households, depicting the alternative combinations of environmental quality (E) or noise pollution and house value (V) available in the short-run.

Consistent with utility maximization is an individual's expenditure function, I $(\mathrm{E})$, showing the amount households would be willing to spend, ceteris paribus, for alternative levels of environmental quality. Equilibrium exists at the point of tangency between $\mathrm{V}(\mathrm{E})$ and $\mathrm{I}(\mathrm{E})$.

Alternatively, differentiating the house value function with respect to $\mathrm{E}$ gives the marginal purchase price function or implicit supply price function, $\mathrm{P}(\mathrm{E})$, shown in Figure 2. Equilibrium for the household is at point $\mathrm{A}$ where the marginal price function, $\mathrm{P}(\mathrm{E})$, intersects the

Figure 1 - The Opportunity Locus for Households

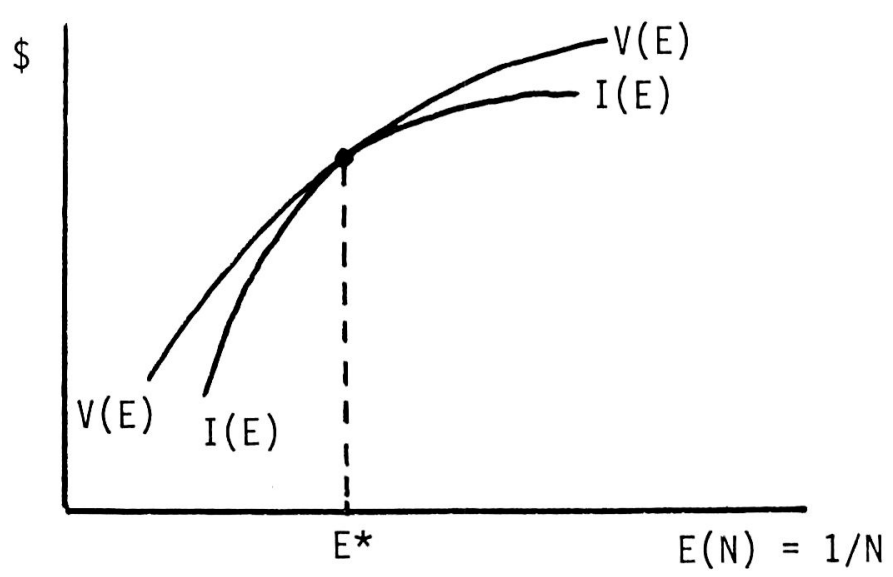


Figure 2 - Household Equilibrium

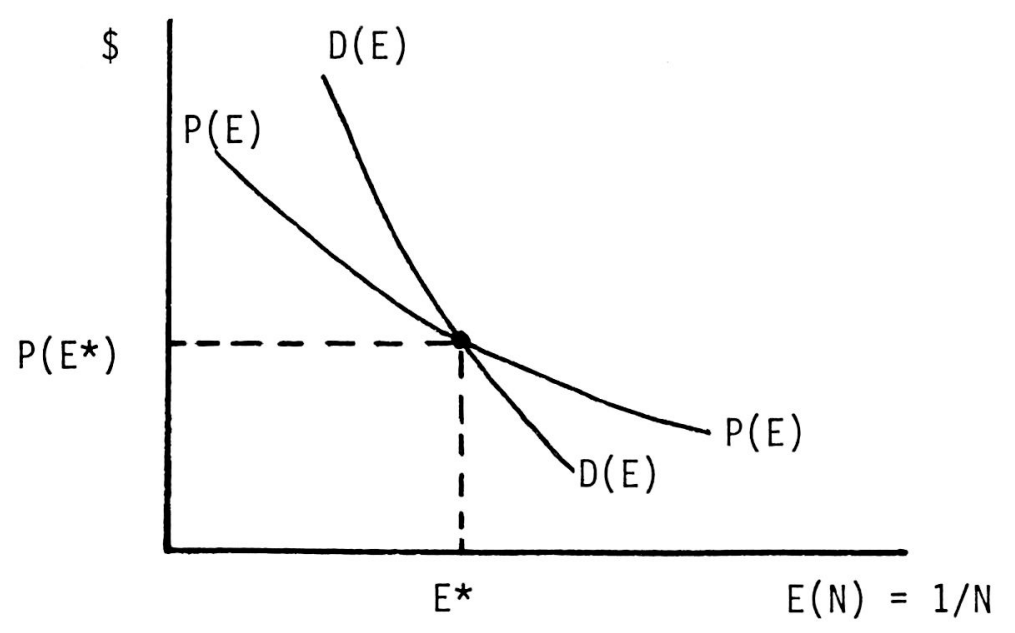

marginal willingness to pay function, $D(E)$. $D(E)$ is derived by differentiating the individual's expenditure function and is equivalent to the inverse of the income compensated demand function for environmental quality. Second order, stability conditions require $\mathrm{I}(\mathrm{E})$ to be more convex than $\mathrm{V}(\mathrm{E})$; that $\mathrm{D}(\mathrm{E})$ intersects $\mathrm{P}(\mathrm{E})$ from above.

From the above discussion, we may conclude, therefore, that each point on the opportunity locus indirectly provides information about one point on the income compensated demand curve for noise abatement as reflected in revealed preference for environmental quality. If a nonlinear specification of the opportunity locus is estimated, it is possible to construct a series of implicit equilibrium prices for noise abatement (i.e., increases in environmental quality) which may be combined with observed values of noise intensity to create a set of price/ quantity relations. ${ }^{2}$ These can then be used for purposes of demand estimation. ${ }^{3}$

\section{REGRESSION RESULTS}

In keeping with the introductory remarks, a log-linear stochastic specification of the environmental quality-house value gradient given by Equation 2 is estimated using ordinary least squares.

$$
\begin{aligned}
\text { House Value }=\mathrm{v} & \text { (House Size, Accessibility, Environmental } \\
& \text { Quality, Neighborhood Quality, Local Col- } \\
& \text { lective Goods) }
\end{aligned}
$$

The data for this analysis are derived from information concerning a sample of "representative" census tracts within the thirty-five planning areas of the city of Los Angeles. ${ }^{4}$ To qualify as a representative census tract, a tract must be located in the center of a city planning 
area since it is presumed that tracts in these locations would most clearly reflect the influences of the characteristics describing the particular planning area in which it is situated. Census tracts near planning area boundaries are not considered representative because house value data from these tracts may reflect unaccounted for external or spill-over effects between contiguous planning areas. ${ }^{5}$

House value (HVAL) and house size (SIZE) are measured by the median value of owner-occupied house units and the average number of rooms for owner-occupied housing units, respectively. Accessibility (ACCE) is measured by the relative quality and convenience of bus service in the planning areas. Quality and convenience are measured by the sum of the average times spent walking to the nearest bus stop and waiting for a bus to arrive, weighted by the average number of trips per day. More traditional indicators of accessibility such as the distance or travel time to the central business district are not utilized because it seems unreasonable to assume that economic activity is concentrated at one location; economic opportunities and activities are widely dispersed through out the city of Los Angeles.

The level of environmental quality (NOIS) is measured by the reciprocal of the relative noise intensity from aircraft over the city planning areas. Relative noise intensity is measured by a weighted figure of the percent of each planning area that is subject to noise levels equal to or greater than 90 decibels. Those areas experiencing a noise intensity equal to or greater than 100 decibels are given twice the weight of other areas so as to account for the phenomenon that 100 decibels is typically perceived as being twice as loud as 90 decibels. Because the data are based on actual 1970 measurements and estimates of 1990 aircraft noise intensities, it is presumed that the variable accounts for on-going programs attempting to reduce noise intensities.

Neighborhood quality and land use characteristics (NEIG) are measured by a scalar reflecting (1) landscaping, (2) amount of litter, (3) number of vacants lots, (4) street conditions, (5) convenience factors, (6) land use, (7) lot size, (8) dwelling size, and (9) house structures. This scalar measure is based on subjective rankings of each planning area by the Los Angeles City Planning Department after evaluation of infrared aerial photographs of Los Angeles City.

The availability of locally provided collective goods ( $\mathrm{SCHO}$ ) is measured by the median reading score on the Iowa Tests for Education Development weighted by school size and the proportion of each school neighborhood within a planning area. School neighborhoods are delineated on the presumption that in the long-run pupils are most likely to attend schools closest to their homes. Each school, therefore, is assigned a hypothetical neighborhood extending half the distance to the next school. This measure is not meant to imply

that other local public goods are irrelevant to the site choice problem. However, measures of other services are not available at the spatial 
level of this analysis. Also, it may be argued that the neighborhood quality variable reflects aspects of other municipal services (e.g., parks and recreation services are reflected in the land use and landscaping components). ${ }^{6}$

In Table 1 is presented a summary of the estimated effects of noise pollution and the other explanatory variables on the median value of owner-occupied housing. The parameter estimate for the environmental quality variable (NOIS) suggests that house value is relatively inelastic with respect to noise intensity differentials. It is estimated that, ceteris paribus, a residence of average value subjected to an average level of noise pollution will decline in value by twenty-four dollars if the weighted area subjected to noise intensities of 90 decibels or more increases by one percent.

Overall, the coefficient estimates suggest that the size of structure and the availability of public schools are the primary determinants of house value. This seems plausible since homeowners are likely to have children and would, therefore, be responsible to both the availability of educational facilities and the level of housing services.

The insignificance of the neighborhood variable may reflect the influence of self-owned yards and open spaces in reducing the effect of neighborhood characteristics on site choice since many neighborhood amenities are jointly supplied with housing services. It should be noted, however, that there exists a degree of collinearity between the school and neighborhood variables, introducing a problem of near multicollinearity. This implies that the regression equation may be attributing some of the neighborhood quality effects to the above variable and that strict interpretation of the coefficient estimates for the two related variables should be done with care.

The insignificance of the accessibility coefficient may be reflecting two factors: First, public transportation may not be an important part

\section{TABLE 1 - THE HOUSEHOLD OPPORTUNITY LOCUS}

\begin{tabular}{lcc}
\hline $\begin{array}{l}\text { Independent } \\
\text { Variable }\end{array}$ & $\begin{array}{c}\text { Parameter } \\
\text { Estimate }\end{array}$ & $\begin{array}{c}\text { Standard } \\
\text { Error }\end{array}$ \\
\hline SIZE & 1.5762 & 0.24872 \\
ACCE & -0.078572 & 0.10237 \\
NEIG & -0.013568 & 0.14693 \\
SCHO & 0.28992 & 0.10407 \\
NOIS & 0.015766 & 0.010909 \\
INTERCEPT & -3.1943 & \\
\hline
\end{tabular}

All Variables Measured in Natural Logagrithms

$\mathrm{R}^{2}: \quad .83$ 
of the overall transportation network servicing Los Angeles. As such, differentials in the quality and convenience of bus service may have little effect on residential choice. Secondly, as found by other writers, (9), this outcome may reflect the relative homogeneity because of advancing transportation technology and the emphasis on personal transportation modes, of residential locations vis-a-vis accessibility.

Differentiating the opportunity locus with respect to NOIS yields an estimate of the marginal purchase price function for environmental quality associated with noise pollution.

$$
\hat{\mathrm{P}}(\mathrm{NOIS})=(.01576)(\mathrm{HVAL} / \mathrm{NOIS})
$$

Using the price generated from.this function and the observed values for HVAL and NOIS, it is possible to construct a price/quantity series that can be used to estimate the demand equation (i.e., marginal willingness to pay function) for noise abatement subsumed in the simultaneous equation system:

$$
\begin{aligned}
& \text { NOIS }^{\mathrm{D}}=\mathrm{D}(\hat{\mathrm{P}} \text { (NOIS), INCO, POPU }) \\
& \text { NOIS }^{\mathrm{S}}=\mathrm{S}(\hat{\mathrm{P}} \text { (NOIS), CLIM, DIST }) \\
& \text { NOIS }^{\mathrm{D}}=\text { NOIS }^{\mathrm{s}}
\end{aligned}
$$

where: $\quad$ NOIS $\stackrel{\mathrm{D}, \mathrm{S}}{=}$ the demand and supply quantities of Environmental Quality, respectively

$\hat{\mathrm{P}}(\mathrm{NOIS})=$ the estimated marginal purchase price of Environmental Quality (i.e., noise abatement)

INCO $=$ median family income

POPU $=$ planning area population

$\mathrm{CLIM}=$ planning area climate

DIST $=$ distance to Los Angeles International Airport

The specification of the demand equation reflects the traditional hypotheses that the demand for a commodity is related to both the price of the commodity and income. ${ }^{7}$ Assuming that environmental quality is a normal good it is expected that income will be positively related to the level of demand for environmental quality. Population is included in the specification so that we may indirectly test the "publicness" in consumption of noise pollution. Intuitively it appears that environmental quality (or noise pollution) closely approximates a pure public good; the consumption by one individual does not reduce or interfere with the consumption possibilities of other individuals. If this be so, it is hypothesized that the population variable will have an associated zero (i.e., insignificant) coefficient. 
The specification of the supply equation is such that it incorporates technological aspects of sound transmission which affect the strength of noise propagation and therefore the level (supply) of experienced noise. CLIM is included to account for the refraction of noise because of differences in wind conditions and humidity, while DIST accounts for the changes in sound levels over distances, or the air absorption of noise. ${ }^{8}$

In Table 2 is presented the two-stage least squares estimate of the demand relation for environmental quality. A log-linear specification has been utilized, thus yielding direct estimates of demand elasticities. Overall, the results are encouraging since the price elasticity is negative and the income elasticity is positive. The parameter estimates suggest that the demand for noise abatement (environmental quality) is both price and income inelastic, though the estimated price-elasticity coefficient is close to unity, and we are unable to reject the null hypothesis that the "true" coefficient value is equal to one. Because the population coefficient is insignificant within standard levels of confidence we may conclude that our intuition about the "publicness" of noise pollution is not incorrect; changes in the demand for noise abatement are not associated with changes in population. The consumption by one individual does not affect the consumption of others. Because noise abatement is indivisable, nonexcludable, and apparently characterized by nonrivalness, we may conclude that it closely approximates the polar case of a public good.

Given the demand function for environmental quality and the presumed relation between environmental quality and noise pollution, it is possible to estimate the benefit (dollar value) associated with nonmarginal changes in aircraft noise by integrating over the individual's

\section{TABLE 2 - THE DEMAND FUNCTION FOR ENVIRONMENTAL QUALITY}

(Two Stage Least Squares Estimates)

\begin{tabular}{lcl}
\hline Independent & $\begin{array}{c}\text { Parameter } \\
\text { Estimates } \\
\text { (elasticities) }\end{array}$ & $\begin{array}{c}\text { Standard } \\
\text { Error }\end{array}$ \\
\hline P(NOIS) & -0.9997 & 0.05067 \\
INCO & 0.6993 & 0.07062 \\
POPU & 0.05433 & 0.06423 \\
INTERCEPT & -1.064 & 0.8157 \\
\hline
\end{tabular}

All Variables Measured in Natural Logrithms

$\mathrm{R}^{2}$ : Not reported since under the two stage least squares technique it is not constrained to the $(0,1)$ interval. 
demand curve and then summing over the relevant population. This benefit figure may be considered the compensating variation associated with noise pollution, or the amount households would be willing to pay for a decrease in experienced noise levels.

For expository purposes consider the paradigm of a specific type noise abatement program that reduces experienced noise intensities to such a degree that there is a $25 \%$ improvement in environmental quality for all individuals. The relevant benefit estimates are given in Table 3. On the basis of the above estimated demand relation and assuming a Los Angeles city population of 2.8 million people, it is estimated that the aggregate monetary benefit accruing to residents because of the hypothetical noise abatement program equals 104 million dollars. Inasmuch as this estimate may seem unreasonable high, per capita and per household (estimating 2.68 people per household) figures are also presented so as to provide additional perspective to the benefits (costs) associated with noise reductions. On a per capita basis, our estimates suggest that an individual would be willing, on average, to pay thirty-seven dollars for a twenty-five percent improvement in environmental quality, or approximately sone-hundred dollars per household. Though, because of the small sample size and the methods of measurement, these estimates must be considered tentative, first approximation, they do provide some insight into the dollar magnitudes involved. Similarly, though no conclusive statements can be made about the net gains from noise abatement without the concomitant cost figures of the abatement programs ${ }^{9}$, the results suggest that the potential exists for a significant welfare gains from noise reduction programs. This is particularly true for those pro-

\section{TABLE 3 - BENEFIT ESTIMATES FROM A HYPOTHETICAL NOISE ABATEMENT PROGRAM}

\begin{tabular}{ccc}
\hline $\begin{array}{l}\text { Aggregate } \\
\begin{array}{c}\text { Benefits }=\mathrm{B} \\
\text { (millions of } \\
\text { dollars) }\end{array}\end{array}$ & $\begin{array}{l}\text { Per Capita } \\
\text { Benefits }=\overline{\mathrm{b}} \\
\text { (dollars) }\end{array}$ & $\begin{array}{c}\text { Household } \\
\text { Benefits } \\
\text { (dollars) }\end{array}$ \\
\hline 104 & 37 & 100 \\
\hline
\end{tabular}

Based on a 25 percent improvement in experienced Environmental Quality

$$
\begin{aligned}
& \mathrm{B}=\sum \mathrm{b}^{1} \\
& \mathrm{~b}^{\mathrm{i}}=\int_{\mathrm{E}^{1}}^{\mathrm{E}^{*}} \mathrm{D}(\mathrm{E}) \mathrm{dE}
\end{aligned}
$$


grams that have very low implementation and administrative costs such as the redirection of flight patterns or adjustment of landing procedures.

\section{CONCLUSION}

It has been reiterated that the spatial distribution of environmental characteristics influences site choice and, therefore, residential property values. This implies that information about the demand for environmental quality is subsumed in observed housing prices, and suggests an indirect method of generating a set of implicit prices for environmental characteristics. By estimating a nonlinear hedonic relation of house value that includes a measure of noise pollution it is possible to derive a marginal purchase price function for noise abatement (environmental quality). This function can then be used to construct a price series for environmental quality as affected by noise pollution that can be applied in a demand analysis. The premise behind this procedure is that households, in their attempts to maximize utility, equate their marginal willingness to pay for environmental quality to its implicit marginal purchase price.

Applying this method, a demand relation for noise abatement is estimated. The results from the analysis are encouraging in that the price elasticity is negative, while the income elasticity is positive; results we a priori expect. The coefficient estimates (point estimates) suggest that the demand is both price and income inelastic, though we cannot reject the hypothesis that demand is unitary price-elastic. The specification of the demand relation also permits a test of the "publicness" of environmental quality in consumption. The results indicate that noiserelated environmental quality closely approximates a pure public good since changes in demand are not associated with changes in population.

Having derived the demand relation, it is possible to estimate the aggregate and per capita benefits from a nonmarginal reduction in noise levels. The results from this stage of the analysis imply that substantial gains may accrue to households from noise abatement programs. The results are partial in nature, however, since a full analysis must also consider the costs associated with noise abatement programs. It may be argued, though, that the benefit estimates presented underestimate the "true" value of noise reductions. This downward bias results from the use of information in the opportunity locus which reflects the compensating variation associated with environmental differentials-the amount households are willing to pay for a beneficial change. This amount is necessarily constrained by income and need not correspond to equivalent variation - the amount households must be compensated to undergo an increase in noise pollution.

\section{FOOTNOTES} 1The compensating variation may be con-
sidered a lower bound to to the "true" cost of
noise pollution since it shows the amount

households are willing to pay for a reduction in experienced noise levels. This amount is necessarily restricted by income and need not 
correspond to the amount households would have to be paid to compensate them for an increase in noise pollution.

2Lucus (6) has argued that a nonlinear hedonic price function can be derived from a non-degenerate Lancastrian consumer problem implying that households have different preferences, or different incomes and non-homothetic indifference maps. Triplett (14) however, has suggested that the hedonic price function is analogous to the budget constraint in traditional consumer theory. Thus its functional form has nothing to do with consumer preferences and is limited only by its applicability to demand analysis.

${ }^{3}$ As with traditional demand analysis there is the problem of aggregating over individual. Triplett (14: 320) indicates that it is not appropriate in an hedonic context to circumvent this by assuming the fiction of a representative consumer since the assumption would place restrictions on the number of varieties of a good observable in the market. This would imply that we are forced to ignore the aggregation problem at this stage by presuming that it is not the individual consumer that interests us, but average behavior. (2: 1168). I would suggest, however, that it is still permissible to appeal to the fiction of a representative consumer with the restriction that indifference curves in characteristic space be nonparallel. Thus, it would be possible to observe more varieties than characteristics. In fact, what we would observe is individuals in different income classes consuming different varieties of the same commodity; behavior that is not uncommon.

${ }^{4}$ The data were taken from (5) and (15).

5 By using a reduced sample size it is therefore hoped that we can control for factors that are not quantifiable or for which data are not available thus reducing any possible bias in our parameter estimates.
${ }^{6}$ Though a limited number of structural variables are used to explain differentials in residential property values over 80 percent of the observed variation in value is explained by the estimated model. This is not surprising since previous investigation of the relationship between house value and structural characteristics (the most important of which appears to be size of structure) explained the greatest proportion of variation while less aggregate house characteristics (e.g., type of flooring, had limited, marginal explanatory power $(4: 127$, 142, 145).

Implicit in the above formulation is the assumption that residents face the same prices for other goods. Thus, price for substitute and complimentary commodities are not included in the stochastic analogue of the demand equation. Though it is recognized that this question of constant prices is an empirical question, it does not seem to be an unreasonable assumption since the data are drawn from one city in a large metropolitan area.

8 Though the concept of a supply equation for noise pollution may seem counterintuitive, it is offered in the spirit that house value differentials may provide a signal for the initiation of collective (i.e., political) action to limit or curtail the production of noise pollution. Thus, the implicit market for environmental quality may be characterized by demand and supply equations that are both downward sloping in the price dimension. The estimate supply equation is:

$$
\begin{aligned}
\mathrm{Q}_{4}= & 11.74+.15 \text { CLIM }-.61 \text { DIST } \\
& (3.45)(.12) \\
& -1.24 \mathrm{P}(\text { NOIS }) \\
& (.15)
\end{aligned}
$$

It has been estimated that it would cost the major airlines between 880 million dollars and 1 billion dollars to modify their older aircraft so that they meet existing (1969) federal noise standards (92-108 decibels).

\section{REFERENCES}

1. Berry, Brian J. L. et al. Land Use, Urban Form and Environmental Quality. Chicago: The University of Chicago, Department of Geography, 1974.

2. Brown, Alan and Angus Deaton. "Surveys in Applied Economics: Models of Consumer Behavior." Economic Journal 82 (1972): 1145-1236.

3. Freeman, A. Myrick III. "On Estimating Air Pollution Control Benefits From Land Values Studies." Journal of Environmental Economics and Management, 1 (1974): 74-83.

4. Grether, D. M. and Peter Mieszkowski. "Determinants of Real Estate Values." Journal of Urban Economics, 1 (1974): 127-146.

5. Los Angeles Department of City Planning. "A Model for Subsidized Housing Location." October, 1973.

6. Lucus, Robert E. B. "Hedonic Price Functions." Economic Inquiry, 12 (June, 1975), 157-178.
7. Muellbauer, John, "Household Production Theory, Quality, and the 'Hedonic Technique'." American Economic Review, 64 (1974): 977-994.

8. Muth, Richard F. Cities and Housing. Chicago: The University of Chicago Press, 1969.

9. Nelson, John P. "Residential Choice, Hedonic Prices and Demand for Urban Air Quality: Unpublished Paper, The Pennsylvania State University, July, 1975.

10. Plessas, Demetrius J. "Airport Noise: Some Analytic and Policy Perspectives." Land Economics, 48 (1973): 14-21.

11. Ridker, Ronald G. and Henning, John A. "The Determinants of Residential Property Values with Special Reference to Air Pollution." Review of Economics and Statistics, 50 (1967): 246-257.

12. Rosen, Sherwin, "Hedonic Prices and Implicit Markets: Product Differentiation in Pure Competition." Journal of Political Economy, 82 (1974): 34-55. 
13. Sachman, Julius L. "Proximity Damagers." The Appraisal Journal, 37 (1969): 177-199.

14. Triplett, Jack E. "Consumer Demand and Characteristics of Consumption Goods" in Household Production and Consumption, Nestor E. Terleckyj (ed.) New York: Na- tional Bureau of Economic Research, 1976.

15. U. S. Department of Commerce. 1970 Census of Population and Housing (Census Tracts): Los Angeles-Long Beach, Standard Metropolitan Statistical Area. 